\title{
Functional adaptations of Begonia oxysperma A. DC. and Begonia ramosii Merr. (Begoniaceae) revealed through morpho-anatomical analyses
}

\author{
Wilfredo B. Barrera Jr.*, Viverly Joy D. De Guzman, Rose Mel R. Mergilla
}

\begin{abstract}
Populations of Begonia occur along the altitudinal gradients of Mt. Banahaw de Lucban. Begonia ramosii Merr. populations occur at lower altitudes and are gradually replaced by Begonia oxysperma A. DC. at higher elevations. This suggests the possibility of local adaptations and phenotype localization. Populations of Begonia were assessed and examined for phenotypic variability to provide information about habitat-driven traits and functional adaptations. Analysis of functional traits in 19 populations of $B$. oxysperma and 8 populations of B. ramosii using morpho-anatomical techniques confirmed these hypotheses. Phenolic vacuolar inclusions, anthocyanin pigmentation in young leaves and stems, presence of medullary vascular bundles and secondary growth, chlorophyll $a$ concentration, trichome density in vegetative parts and stomatal density were observed to vary either intraspecifically or interspecifically which suggest functional adaptation. These preliminary results provide an interesting avenue for plant evolutionary and ecological studies using Begonia as a model plant species.
\end{abstract}

Keywords: adaptation, environmental gradient, habitat-driven traits, Mt. Banahaw, variation

\section{Introduction}

The importance of microhabitat of a species is widely recognized in a variety of ecological phenomena. In response to several environmental conditions, many species of plants exhibit wide ranges of phenotypic variability. These variations in phenotypic expression are ecologically important and are key components of species adaptation and persistence. Functional traits are those properties of an organism or a part of an organism that strongly influence fitness through their effects on growth, reproduction and survival (Shah et al., 2019). In plants, phenotypes expressed differently along environmental gradients as a result of adaptive mechanisms are termed localized phenotypes, whereas geographically unstructured phenotypes that occur throughout the range of the species are called generalized phenotypes (Bradshaw, 1965; Schlichting \& Smith, 2002). Environmental heterogeneity is one of the factors that play a major role in the occurrence of such phenotypes

\footnotetext{
${ }^{1}$ Mathematics and Natural Sciences Department, College of Arts and Sciences, Southern Luzon State University, Lucban, Quezon 4328 Philippines
}

*Corresponding email: : barrerawilfredojr@gmail.com

Date Submitted: 11 June 2019

Date Accepted: 12 December 2019 demonstrating versatility and diversity of the response of organisms to environmental changes. The occurrence of localized phenotypes among closely related taxa along environmental gradients frequently results in speciation, generating diverse group of organisms (Abbott, 2017; Fitzpatrick, 2012).

Begonia is one of the megadiverse groups of plants in the Philippines with 104 recorded endemic species (Hughes, 2008). Several species such as Begonia oxysperma A. DC. and $B$. ramosii Merr. occur along the altitudinal gradients of $\mathrm{Mt}$. Banahaw de Lucban from the vicinity of the lowlands up to its peak. B. oxysperma belongs to sect. Baryandra A. DC., which has its center of diversity in the Philippines (Rubite et al., 2013). Species in this section are rhizomatous, stemless, monoecious herbs, often lithophytic and associated with riverine habitats and waterfalls (Hughes et al., 2018). On the other hand, B. ramosii belongs to sect. Petermannia (Klotzsch) A. DC. This section tends to be humicolous and occurs in microhabitats with more constant water availability (Rubite, 2013). These two species though belonging to a single genus, possess apparent morphological and anatomical differences and occur along specific altitudinal ranges. Their variations might have been facilitated by phenotypic plasticity or genetic differences which ultimately led to functional adaptations.

Altitudinal gradient is one of the factors that allows morpho-anatomical adaptations resulting to occurrence of 
localized phenotypes or may facilitate the persistence of generalized phenotypes. Körner (2007) stated that altitudinal gradients provide an ideal experimental opportunity for studying the variation of functional traits in plants in response to environmental factors. Mt. Banahaw de Lucban, having a maximum altitude of 1875 meters above sea level (masl) is an ideal system in which to uncover the role of environment in shaping inter- and intraspecific variation and functional adaptation of plants such as Begonia. Several studies regarding the distribution and diversity of plant and animal species have been conducted along the altitudinal gradients of Mt. Banahaw (Almazol \& Quintana, 2009; Banaticla \& Buot, 2005; Gascon et al., 2013; Santiago \& Buot, 2015; de Guia et al., 2018) but the extent by which environmental gradients affect the distributional limits and the occurrence of certain phenotypes have not yet been documented. Moreover, many studies about inter- and intraspecific variations on heterogeneous environment had been conducted (Bosabalidis et al., 2003; de Bello et al., 2015; Yuliani et al., 2015) but not explicitly in the context of Begonia species. Thus, this paper investigated the functional adaptations of $B$. oxysperma and $B$. ramosii along the altitudinal gradients of Mt. Banahaw de Lucban, Philippines using morpho-anatomical techniques.

\section{Materials and Methods}

\section{Study site}

This study was conducted in the northeastern slope of Mount Banahaw de Lucban (Figure 1) which lies between $13^{\circ}$ $55^{\prime}$ and $14^{\circ} 10^{\prime} \mathrm{N}$ latitude and $121^{\circ} 26^{\prime}$ and $121^{\circ} 35^{\prime}$ E longitude. Its peak has an elevation of 1875 masl. It is a protected landscape and among the most important ecosystems in the Philippines serving as habitat for several organisms including numerous endemic species.

\section{Collection of plant samples}

Collection permits were secured from Southern Luzon State University and Department of Environment and Natural Resources (Permit No. 2016-043 LQ; Permit No. 2016-037 LQ) before plant collection. The plant samples were collected from 700 masl up to 1200 masl. A distance of $150 \mathrm{~m}$ on both the left and right sides of the trail was surveyed for the presence of the target species. Fresh, whole plant samples of $B$. oxysperma and $B$. ramosii were collected from the sampling sites. Due to restriction in the collection of plant samples, at least three samples were collected from a population with greater than 10 individuals.

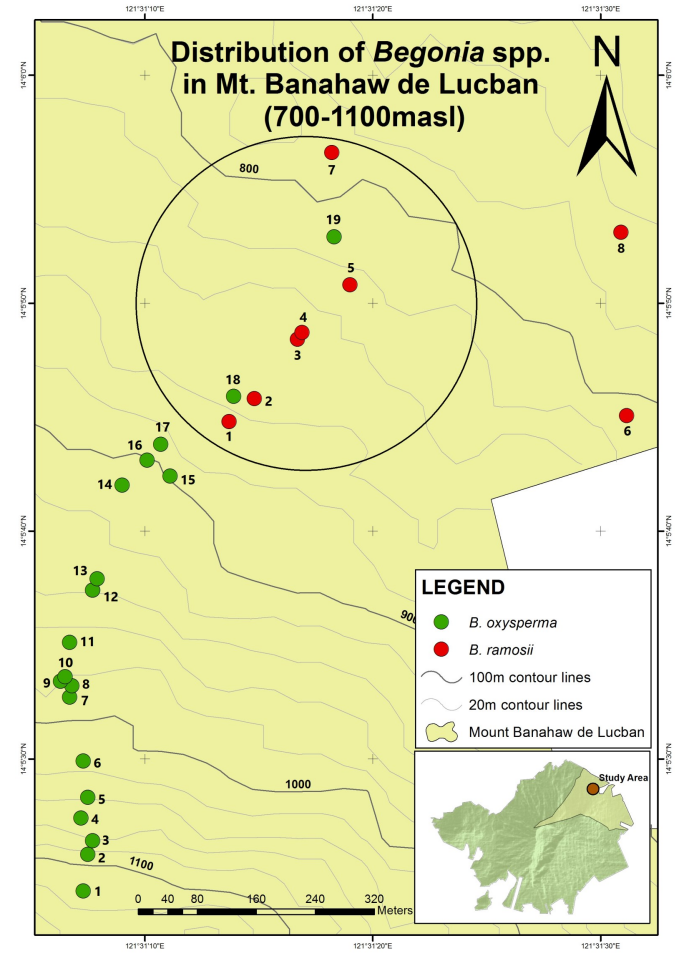

Figure 1. Topographical map showing the distribution of Begonia spp. along the altitudinal gradients of Mt. Banahaw de Lucban. The overlapping population of B. ramosii and B. oxysperma is indicated by a circle.

\section{Morpho-anatomical examination}

The morphology of the vegetative and reproductive parts of Begonia including the quantitative and qualitative characters was examined in situ and in the laboratory. The plant parts were photographed for documentation purposes. A total of 30 tissue sections were used to examine the morpho-anatomy of the species.

Using paraffin and freehand sectioning methods, the anatomy of the vegetative and reproductive parts of the Begonia species was investigated. The standard protocols for plant anatomical investigation such as dehydration, staining, mounting, and microscopy was followed (Robil \& Tolentino, 2016; Ruzni, 1999; Tolentino, 1995). The stomatal density was investigated by observation of paradermal sections while the trichome density and morphology were observed directly under the microscope (Ken- $\alpha$-vision) and then photographed. The distribution of stomata was categorized as single or clustered. The anatomical characteristics of the stomata, guard cells and subsidiary cells were also described.

For the determination of chlorophyll $a$ concentration, $5 \mathrm{~g}$ of leaf lamina obtained from the third leaf relative to the terminal leaf bud was extracted manually in a mortar and pestle 
Table 1. Morpho-anatomical comparison of Begonia ramosii and Begonia oxysperma.

\begin{tabular}{|c|c|c|}
\hline & Begonia ramosii & Begonia oxysperma \\
\hline \multicolumn{3}{|l|}{ Morphological characters } \\
\hline \multirow[t]{2}{*}{ (a) vegetative structures } & $\begin{array}{l}\text { sub-shrub; erect and green or maroon } \\
\text { stem }\end{array}$ & $\begin{array}{l}\text { epiphytic vine; succulent stem; no } \\
\text { apparent anthocyanin pigmentation in any } \\
\text { vegetative parts except for the lamina of } \\
\text { young leaf }\end{array}$ \\
\hline & $\begin{array}{l}\text { petiole has evenly distributed minute } \\
\text { trichomes }\end{array}$ & $\begin{array}{l}\text { petiole has multicellular, non-glandular } \\
\text { trichomes }\end{array}$ \\
\hline \multirow[t]{2}{*}{ (b) reproductive structures } & monoecious & monoecious \\
\hline & dichasial cyme inflorescence & multiparous cyme inflorescence \\
\hline \multirow[t]{3}{*}{ (b1) carpellate flower } & $\begin{array}{l}\text { has five pink tepals with deep pink } \\
\text { pigmentation at the base }\end{array}$ & $\begin{array}{l}\text { not described because all the carpellate } \\
\text { flowers had already developed into fruits }\end{array}$ \\
\hline & $\begin{array}{l}\text { carpels are actinomorphic, yellow in } \\
\text { color, and have three styles associated } \\
\text { with bifid spiraling stigmas }\end{array}$ & \\
\hline & three-winged inferior ovary & three-winged inferior ovary \\
\hline (b2) staminate flower & $\begin{array}{l}\text { has two tepals which are white in color } \\
\text { with deep pink spot at the base }\end{array}$ & $\begin{array}{l}\text { has four tepals, with the outer pair being } \\
\text { orange in color and the inner pair being } \\
\text { pale orange }\end{array}$ \\
\hline (b3) fruit & $\begin{array}{l}\text { dry dehiscent capsules with three wings; } \\
\text { pale pink to green in color }\end{array}$ & $\begin{array}{l}\text { dry dehiscent capsules with three wings; } \\
\text { dark orange to brown in color }\end{array}$ \\
\hline (b4) seed & dark brown and rounded; 0.06 to $0.10 \mathrm{~mm}$ & dark brown, elongated; 0.12 to $0.20 \mathrm{~mm}$ \\
\hline \multicolumn{3}{|l|}{ Anatomical characters } \\
\hline (a) vegetative structures & uniseriate epidermis & uniseriate epidermis \\
\hline \multirow[t]{5}{*}{ (a1) stem } & transverse section has ridges and furrows & transverse section is circular in shape \\
\hline & $\begin{array}{l}\text { internal cortex ( } 3 \text { to } 5 \text { layers of } \\
\text { parenchyma cells) }\end{array}$ & $\begin{array}{l}\text { internal cortex ( } 5 \text { to } 15 \text { layers of } \\
\text { parenchyma cells) }\end{array}$ \\
\hline & $\begin{array}{l}\text { external cortex ( } 3 \text { to } 5 \text { layers of } \\
\text { collenchyma cells) }\end{array}$ & $\begin{array}{l}\text { external cortex ( } 4 \text { to } 7 \text { layers of } \\
\text { collenchyma cells) }\end{array}$ \\
\hline & fascicular vascular bundles & fascicular vascular bundles \\
\hline & $\begin{array}{l}\text { prominent interfascicular region } \\
\text { consisting of purple, rectangular-shaped }\end{array}$ & less prominent interfascicular cambium \\
\hline
\end{tabular}


Table 1 (cont.) Morpho-anatomical comparison of Begonia ramosii and Begonia oxysperma.

(a2) petiole

(a3) adventitious root

(a4) leaf

(a5) paradermal section

(b2) staminate flower

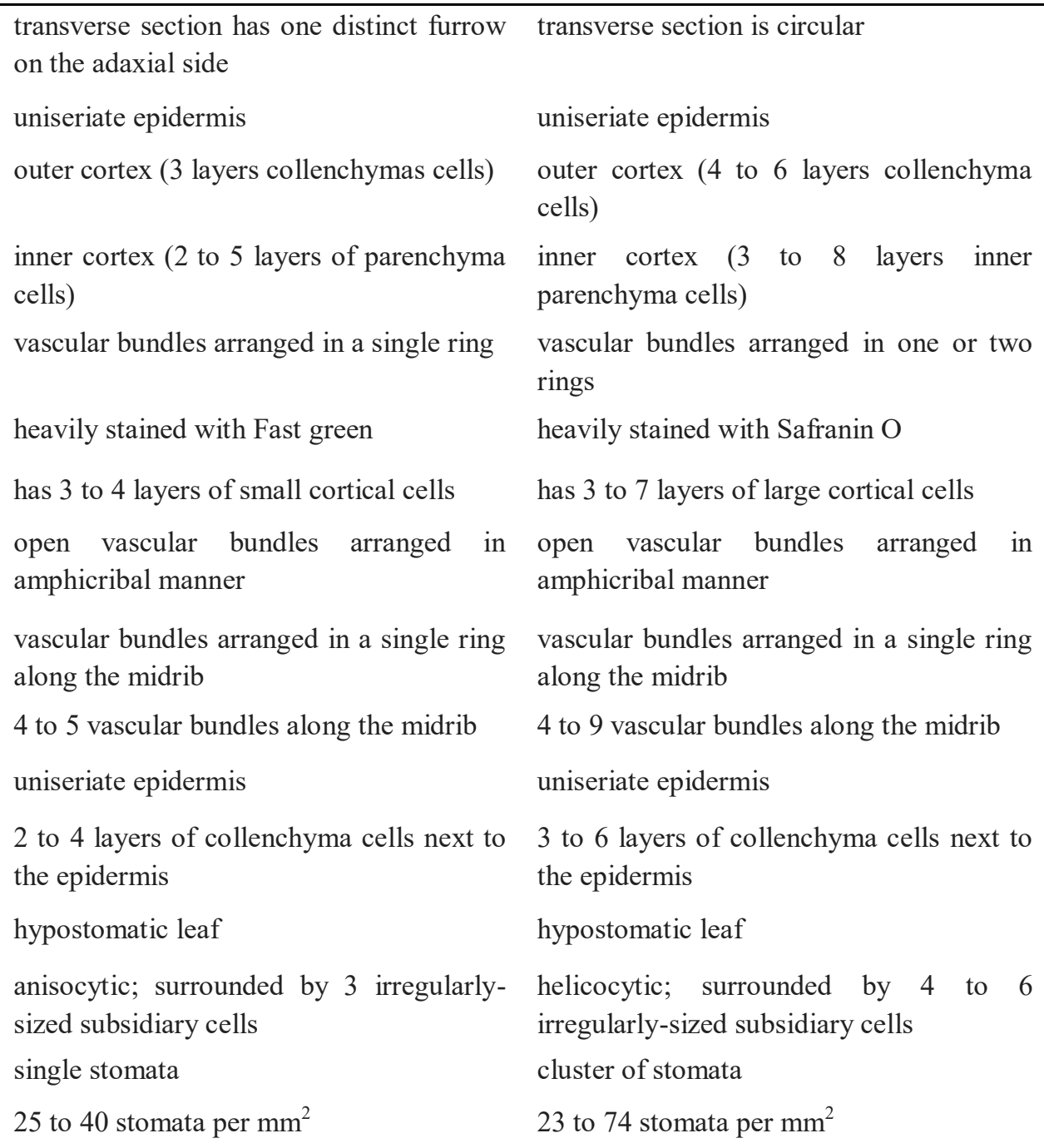

three-loculed and has axile placentation uniseriate darkly-stained epidermal cells locule has large, short and bifurcating funiculi

tepal has uniseriate epidermis

3-5 layers of thin-walled cells between the outer and inner epidermis

anthers are with biseriate walls three-loculed and has axile placentation uniseriate darkly-stained epidermal cells locule has thin separated funiculi not described due to limited number of samples 
using $10 \mathrm{~mL}$ of $80 \%$ acetone as extraction solvent. An aliquot of the leaf extract was transferred in a cuvette and the absorbance reading at $645 \mathrm{~nm}$ and $663 \mathrm{~nm}$ was determined using UV-VIS spectrophotometer.

\section{Measurement of environmental parameters}

Environmental parameters such as elevation, soil and air temperatures, relative humidity and light intensity were measured in all sampling sites. The elevation was determined using Global Positioning System (GPS) while the soil and air temperature was measured using a thermometer. On the other hand, the relative humidity and light intensity were measured using a hygrometer and a light meter, respectively.

\section{Statistical analysis}

The correlation between quantitative characters and environmental parameters was determined using Pearson correlation. Microsoft Excel and SPSS Version 16. 0 were used for all the statistical analysis.

\section{Results}

The distributional range of $B$. ramosii and $B$. oxysperma in Mt. Banahaw de Lucban is very distinct. B. ramosii populations occur at an altitude of 742 to 880 masl, while $B$. oxysperma populations typically occur from 900 to 1115 masl. Two populations of $B$. oxysperma overlapped with $B$. ramosii populations at 780 to 860 masl (Figure 1). The chlorophyll $a$ concentration varied between species and altitude however, no continuous variation was observed. $B$. ramosii had an average chlorophyll $a$ concentration of $28.07 \mu \mathrm{g} / \mathrm{mL}$ while $B$. oxysperma had $11.52 \mu \mathrm{g} / \mathrm{mL}$.

\section{Morphology of vegetative and reproductive structures}

The morphology of the vegetative and reproductive structures of Begonia spp. is summarized in Table 1. Begonia ramosii is a sub-shrub, which possessed erect, green or maroon stem. The presence and degree of anthocyanin pigmentation in the stem differ intraspecifically among $B$. ramosii populations (Figures 2A-D) while no variations were observed in other vegetative parts such as rhizome, petiole and leaf margin. Meanwhile, $B$. oxysperma is an epiphytic vine with succulent stem and no apparent anthocyanin pigmentation in any vegetative parts except for the lamina of young leaf (Figures 3A -B). The anthocyanin pigmentation became greatly reduced in mature leaves.

During the survey, only few individuals were observed to bear reproductive structures such as fruits and flowers. Both species are considered monoecious, bearing both staminate and carpellate flowers on the same plant. The inflorescence of both species is axillary. B. ramosii was observed to possess dichasial cyme inflorescence while $B$. oxysperma had multiparous cymes. The carpellate flowers of $B$. ramosii were observed more often during the sampling period, and only infrequently in $B$. oxysperma because most of flowers of the latter had already developed into fruits. The carpellate flower of $B$. ramosii possesses five pink tepals with deep pink pigmentation at the base. The carpels of B. ramosii are actinomorphic, yellow, and have three styles associated with bifid spiraling stigmas (Figure 4A). Both species possessed three-winged inferior ovary. The staminate flower of $B$. ramosii has two tepals which are white with deep pink spot at the base (Figure 4B). In contrast, $B$. oxysperma has four tepals, with the outer pair being orange and the inner pair being pale orange (Figures 5A-B). The matured fruits of both species are dry dehiscent capsules with three wings. They are unequally sized having oblique wings larger than the lateral wings. The wings of the capsules of both species are turbinate in shape. The capsules of $B$. ramosii are pale pinkgreen (Figure 6A) while those of $B$. oxysperma are dark orangebrown (Figure 6B). The seed of $B$. oxysperma is dark brown, elongated (Figure 6C) and measures 0.12 to $0.20 \mathrm{~mm}$ in length. $B$. ramosii has also dark brown but rounded seeds measuring 0.06 to $0.10 \mathrm{~mm}$ (Figure $6 \mathrm{D}$ ).

\section{Anatomy of vegetative structures}

The anatomical comparison of the vegetative structures of Begonia ramosii and B. oxysperma is presented in Table 1. Both species possessed a uniseriate epidermis. Multicellular branched and unbranched, non-glandular trichomes were also observed on the epidermal surface of the stem of $B$. oxysperma though their densities differed among populations. Most of the populations exhibited moderately dense trichomes while some populations exhibited extremely dense and scarce trichomes. Similarly, $B$. ramosii possessed minute multicellular, non-glandular trichomes.

The stem of $B$. oxysperma in transverse section is circular in shape (Figures 7A-B), while it contains ridges and furrows in B. ramosii (Figures 7E-F). An unusual structure known as medullary vascular bundles was observed in $B$. oxysperma in samples that occur in populations 11, 16 and 18 (Figure 7B). The cortex of $B$. oxysperma is differentiated into an internal and an external zone (Figure 7C). The external zone consists of 4-7 layers of collenchymatous cells while the internal zone consists of 5-15 layers of parenchymatous cells. Similarly, the cortex of B. ramosii is characterized by external zone of 3-5 layers of collenchymatous cells and an internal zone of 3-5 layers of parenchymatous cells (Figure 7F). The vascular system of both species is fascicular, with collateral vascular bundles arranged in 


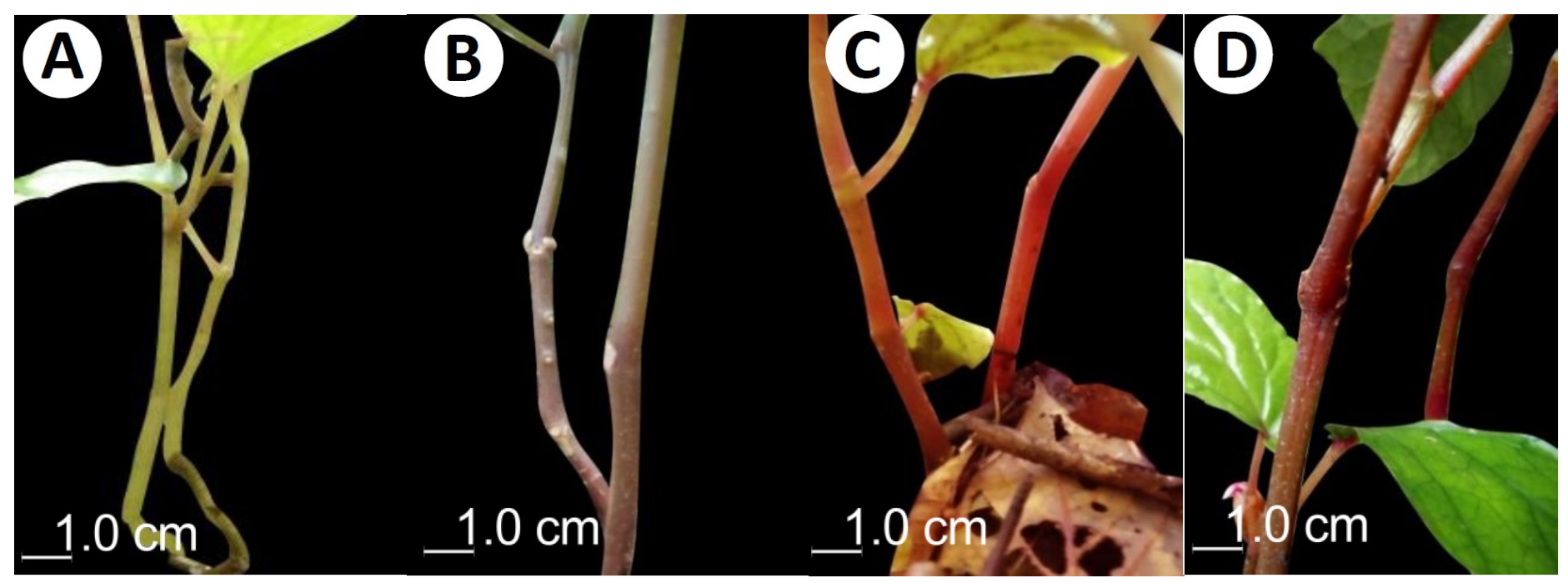

Figure 2. Variation in the degree of anthocyanin pigmentation of the stem of Begonia ramosii.

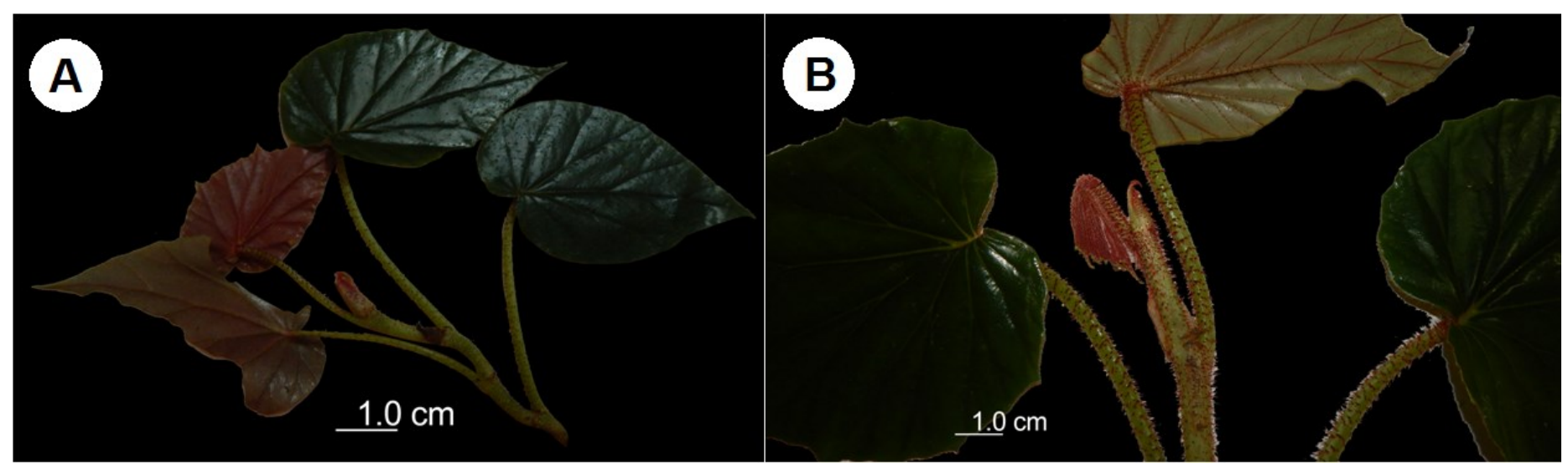

Figure 3. Variation in the degree of anthocyanin pigmentation on the leaves of Begonia oxysperma.

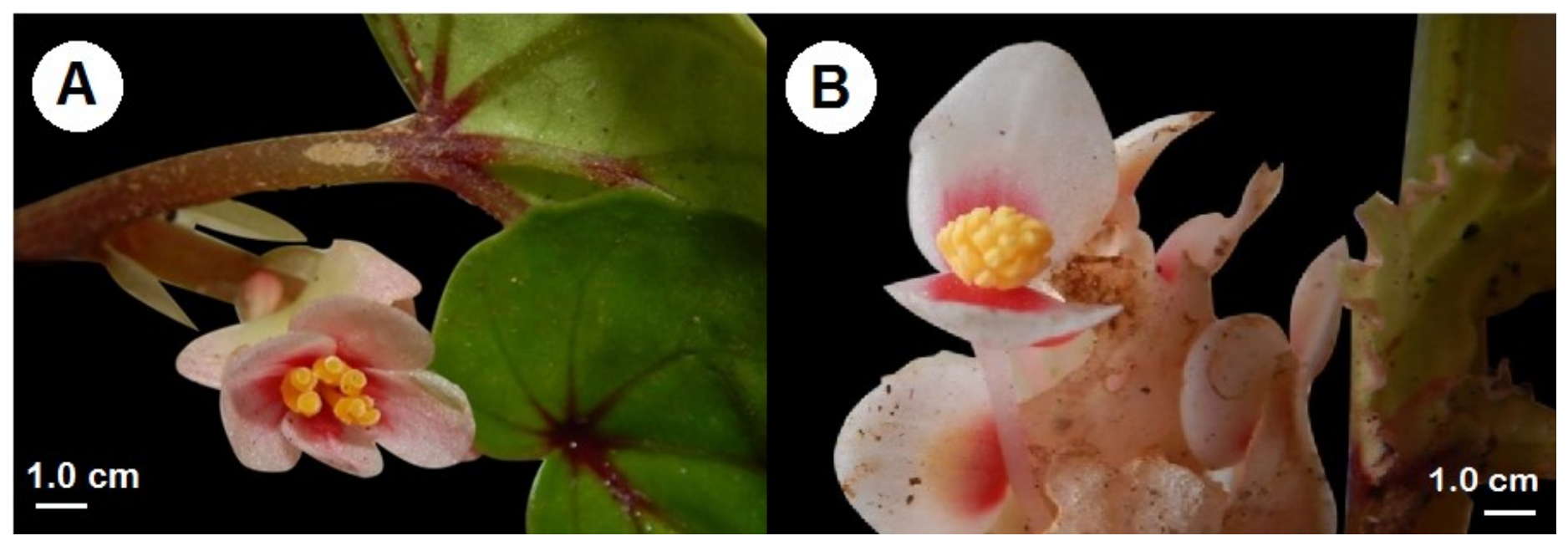

Figure 4. Carpellate flower (A) and staminate flower (B) of Begonia ramosii. 


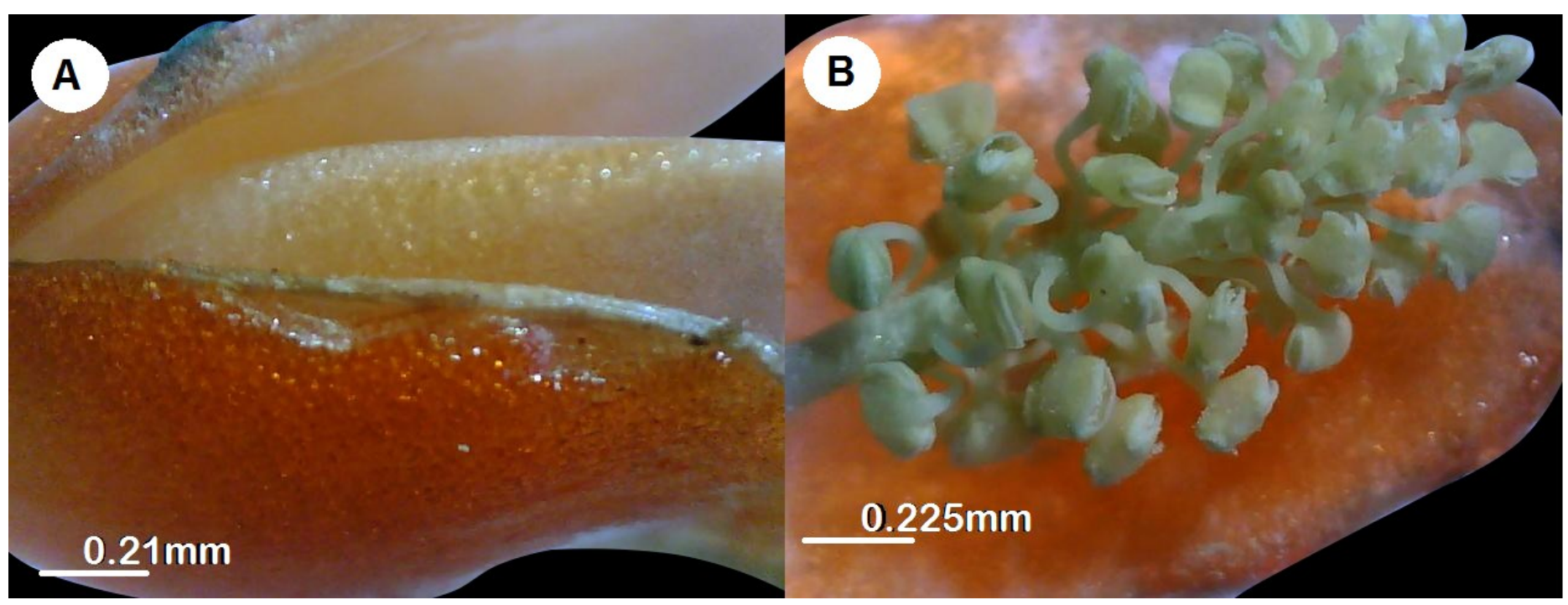

Figure 5. Staminate flower of Begonia oxysperma. (A) enlarged staminate flower showing the tepals; (B) enlarged flower showing the anthers.
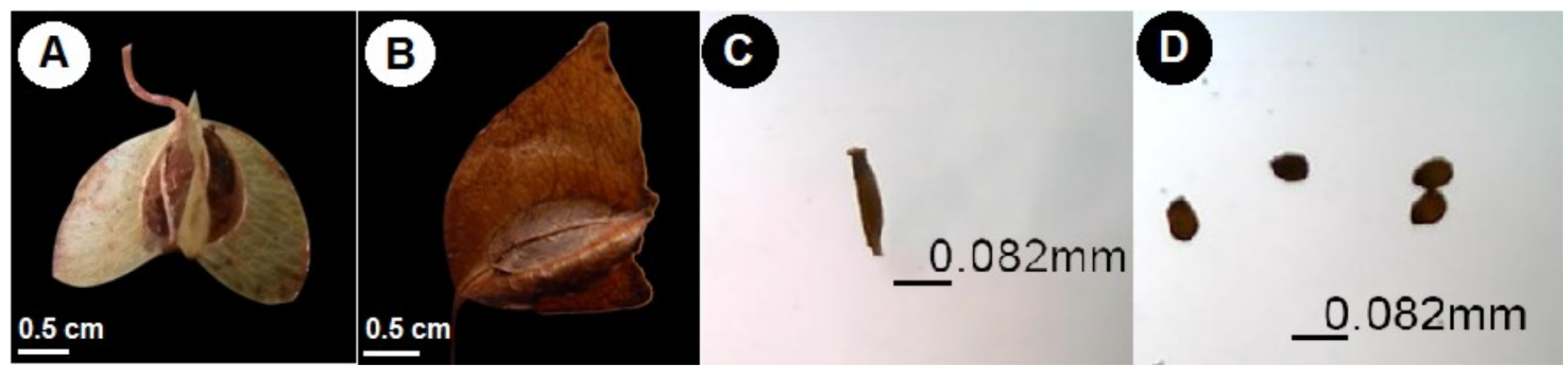

Figure 6. Fruit and seed of Begonia ramosii (A and D) and Begonia oxysperma (B and C).

a single ring. The interfascicular region is very prominent in $B$. ramosii and consists of purple, rectangular-shaped cells (Figure 7G), while the interfascicular region of $B$. oxysperma consists of a less prominent interfascicular cambium (Figure 7D).

The petiole of $B$. oxysperma consists of multicellular, non-glandular trichomes which extend densely from the base of the petiole up to the leaf base. On the other hand, the petiole of $B$. ramosii possesses evenly distributed minute trichomes. In the transverse section, the petiole of $B$. oxysperma is circular (Figure 8A) while $B$. ramosii has one distinct furrow on the adaxial side of the petiole (Figure $8 \mathrm{C}$ ). Both species possess uniseriate epidermis. The cortex of $B$. oxysperma is composed of two distinct layers of basic tissues that include 4-6 layers of outer collenchyma and 3-8 layers of inner parenchyma (Figure 8B). Similarly, the cortex of B. ramosii consists of the same tissues but occur in fewer layers, having 3 layers of collenchymatous cells and 2-5 layers of parenchymatous cells (Figure 8D). The vascular bundles of $B$. oxysperma are arranged in one or two rings, with larger vascular bundles on the inner ring and smaller on the outer ring. Fewer numbers of vascular bundles were observed on individuals that have Cyathea (tree fern) as their host plant while considerably more vascular bundles were observed on individuals that have dead or living woody trees as their host regardless of the population in which they belong. On the other hand, the vascular bundles of $B$. ramosii are arranged on a single ring of alternating large and small vascular bundles that range from 10 to 13 .

The transverse sections of adventitious roots of $B$. oxysperma and B. ramosii are circular. B. oxysperma roots were heavily stained with Safranin O (Figure 9A) whereas B. ramosii were heavily stained with Fast green (Figure 9C). Both species exhibit periderm which covers the inner cortex and vascular cylinders. B. oxysperma has 3-7 layers of large cortical cells while $B$. ramosii has 3-4 layers of comparably smaller cortical cells. The vascular bundles of both species are open, possessing secondary growth and arranged in an amphicribal manner, with the phloem being held external to the xylem (Figures 9B \& D). 


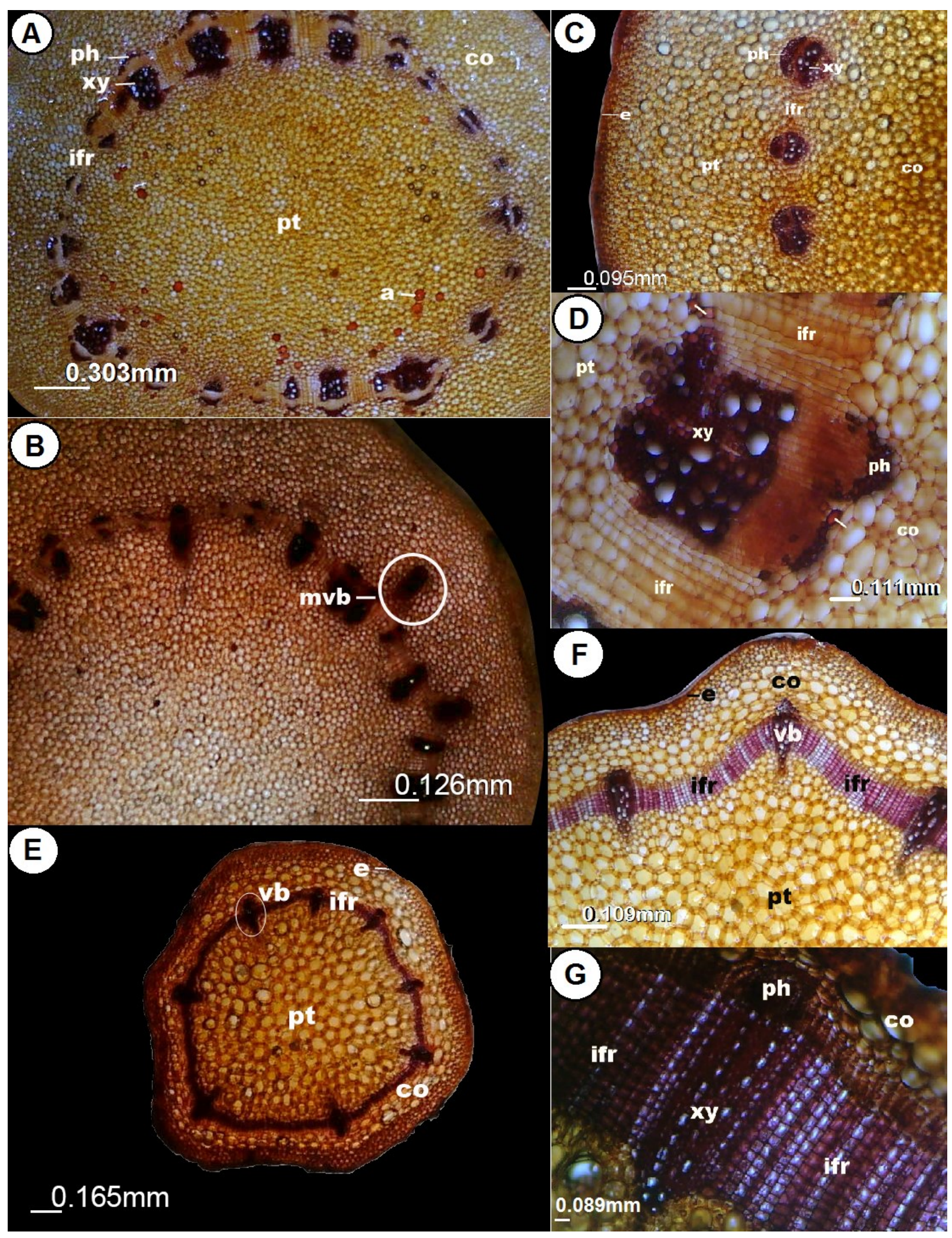

Figure 7. Transverse section of the stem of Begonia oxysperma (A-D) and Begonia ramosii (E-G). Abbreviations - ph: phloem; xy: xylem; co: cortex; pt: pith; a: phenolic compound deposition; e: epidermis; ifr: interfascicular region; mvb: medullary vascular bundle. 


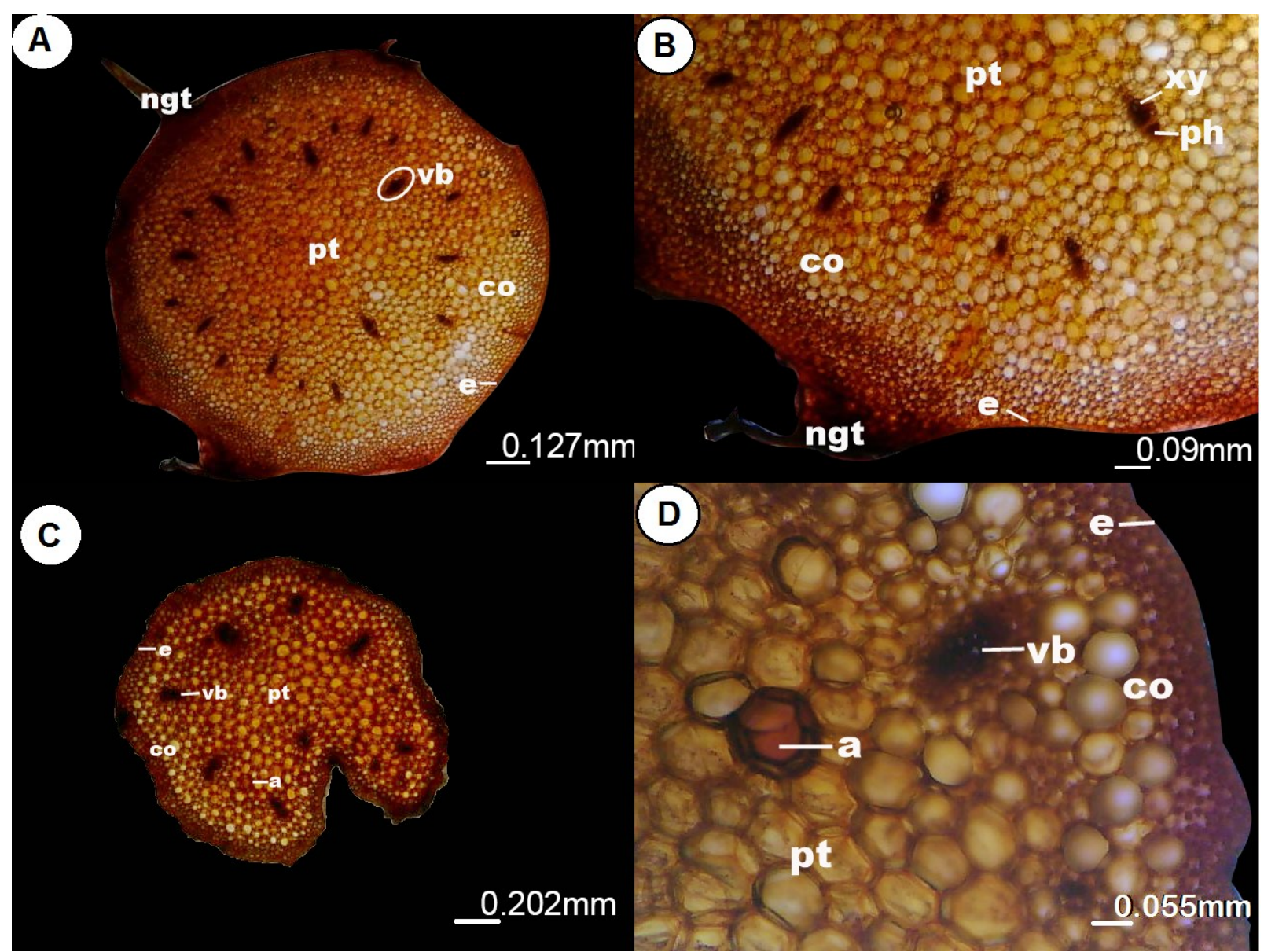

Figure 8. Transverse section of the petiole of Begonia oxysperma (A-B) and Begonia ramosii (C-D). Abbreviations - ngt: non-glandular trichome; vb: vascular bundle; pt: pith; co: cortex; e: epidermis; xy: xylem; ph: phloem; a: phenolic compound deposition.

The leaves of $B$. oxysperma are generally thicker than those of $B$. ramosii while the vascular bundles of both species are arranged in a single ring along the midrib. B. oxysperma populations possessed 4 to 9 vascular bundles along the midrib while $B$. ramosii possessed 4 to 5 vascular bundles along the midrib. Both species possessed uniseriate epidermis. Along the midrib, next to the epidermis are 3-6 layers of collenchymatous cells in $B$. oxysperma while there are 2-4 layers of collenchymatous cells in $B$. ramosii. Parenchymatous cells mostly comprise the ground tissue of the midrib of both species. The leaf laminar portion of $B$. oxysperma is characterized by large cells while that of $B$. ramosii are relatively smaller and thinner. Next to the epidermis on the adaxial surface of $B$. oxysperma are 1-2 layers of palisade mesophyll cells. The palisade mesophyll cells are mostly elongated cells that are tightly packed. On the abaxial surface, spongy mesophyll cells are found which are somewhat spherical in shape.

Paradermal sections showed that both species possessed a hypostomatic leaf, with stomata present on the abaxial leaf surface but absent on the adaxial leaf surface. The stomata of $B$. oxysperma are helicocytic, being helically surrounded by 4 to 6 irregularly-sized subsidiary cells (Figure 10A) while those of $B$. ramosii is anisocytic, being surrounded by 3 irregularly-sized subsidiary cells (Figure 10B). Though both hypostomatic, the stomata of the two species differ in distribution. B. ramosii possesses singly occurring stomata while $B$. oxysperma has stomata that occur in clusters. The stomatal density in $B$. ramosii ranges from 25 to 40 per $\mathrm{mm}^{2}$ though it varies among populations. Meanwhile, the stomatal density of $B$. oxysperma ranges from 23 to 74 stomata per $\mathrm{mm}^{2}$. Higher stomatal density in B. oxysperma might contribute to water-use efficiency and regulation of gas exchange. $B$. oxysperma possesses multicellular, non-glandular trichomes on the leaf epidermal surface. Trichomes were observed mainly on the primary leaf veins while others were observed along the leaf margin and lamina at varying densities. B. ramosii populations also possess minute multicellular, non-glandular trichomes, which were also confined to the leaf veins. 


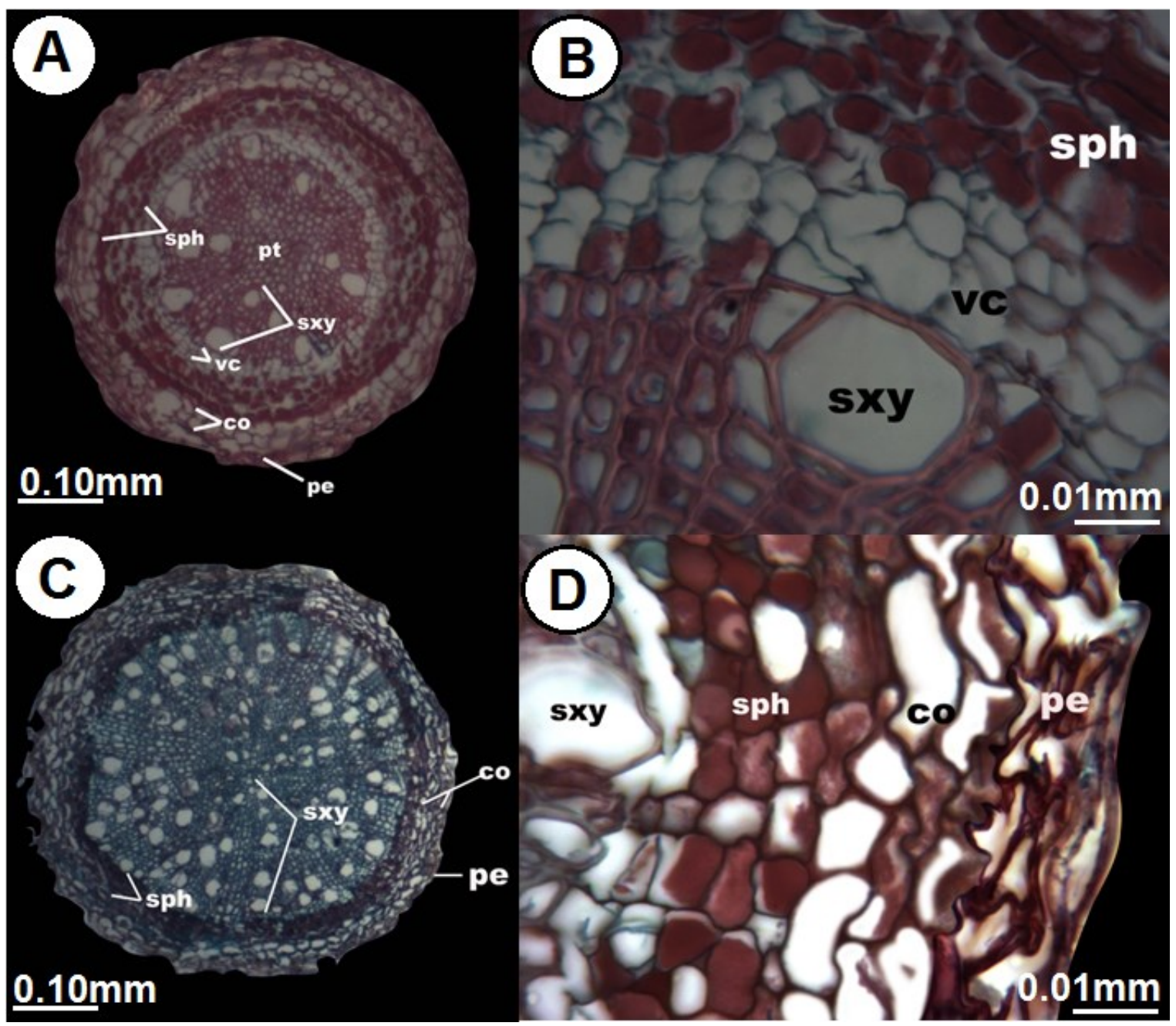

Figure 9. Transverse section of the adventitious root of Begonia oxysperma (A-B) and Begonia ramosii (C-D). Abbreviations — sph: secondary phloem; pt: pith; sxy: secondary xylem; vc: vascular cambium; pe: periderm; co: cortex.

\section{Anatomy of reproductive structures}

The carpellate flowers of both species are three-loculed and exhibit axile placentation. The ovary walls of both species have uniseriate darkly-stained epidermal cells. Each locule of $B$. oxysperma has thin separated funiculi (Figure 11A) while $B$. ramosii has large, short and bifurcating funiculi (Figure 11B). The staminate flower of $B$. ramosii possesses tepals which have uniseriate epidermis (Figure 11C). The epidermal cells on the outer surface of the tepals are larger than those found on the inner surface (Figure 11D). In between the outer and inner epidermal cells are 3-5 layers of thin-walled cells. The anthers are tetrasporangiate and have biseriate walls (Figure 11E).

\section{Discussion}

The distribution of $B$. oxysperma and $B$. ramosii populations overlapped at a certain point, but beyond that, $B$. ramosii was clearly replaced by $B$. oxysperma populations at higher elevations. Thus, they are regarded as ecological specialists, each being found only in a narrow altitudinal range (Griffith \& Sultan, 2012). The first functional trait observed was the anthocyanin pigmentation on the lamina of young leaves of $B$. oxysperma and vegetative structures of $B$. ramosii which might be adaptive for providing protection against the damaging effects of sunlight while they are still in the process of growth and development of their photosynthetic leaf cells (Cutuli et al., 1999; Guo et al., 2008). We classified anthocyanin pigmentation as a localized phenotype being more intense in areas with low 


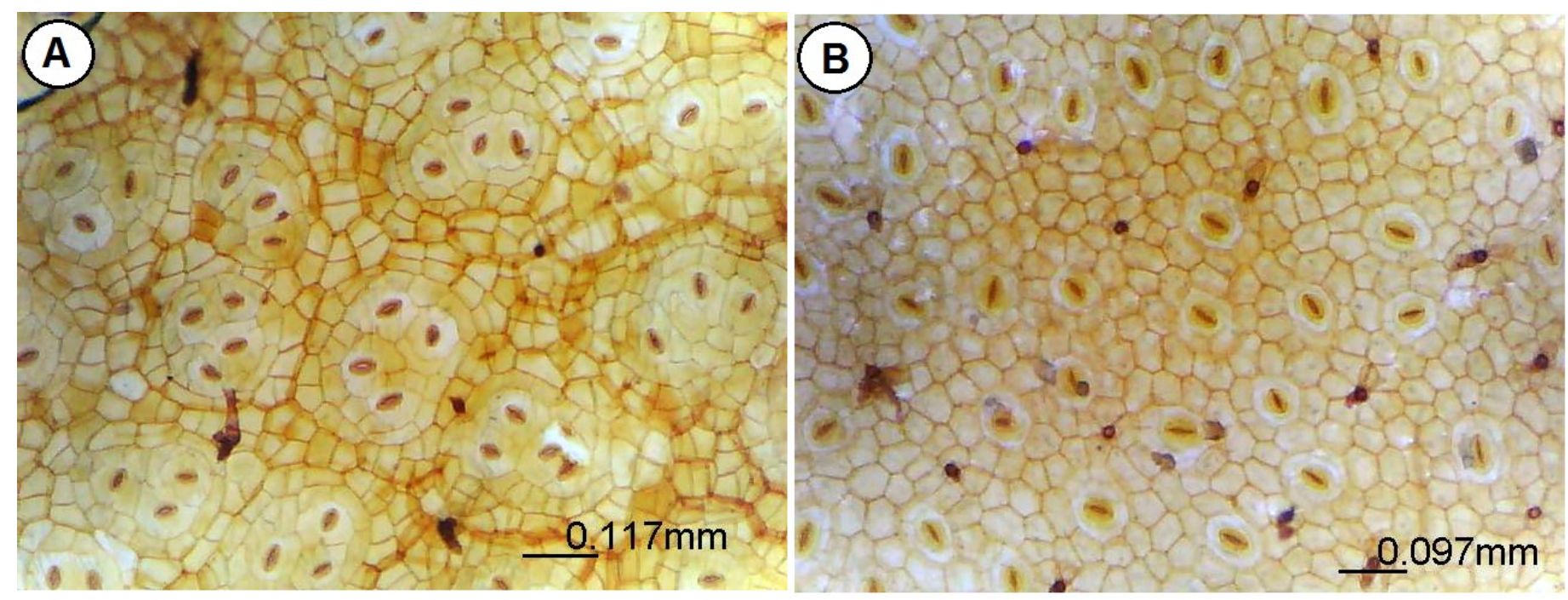

Figure 10. Paradermal section of Begonia oxysperma (A) and Begonia ramosii (B).

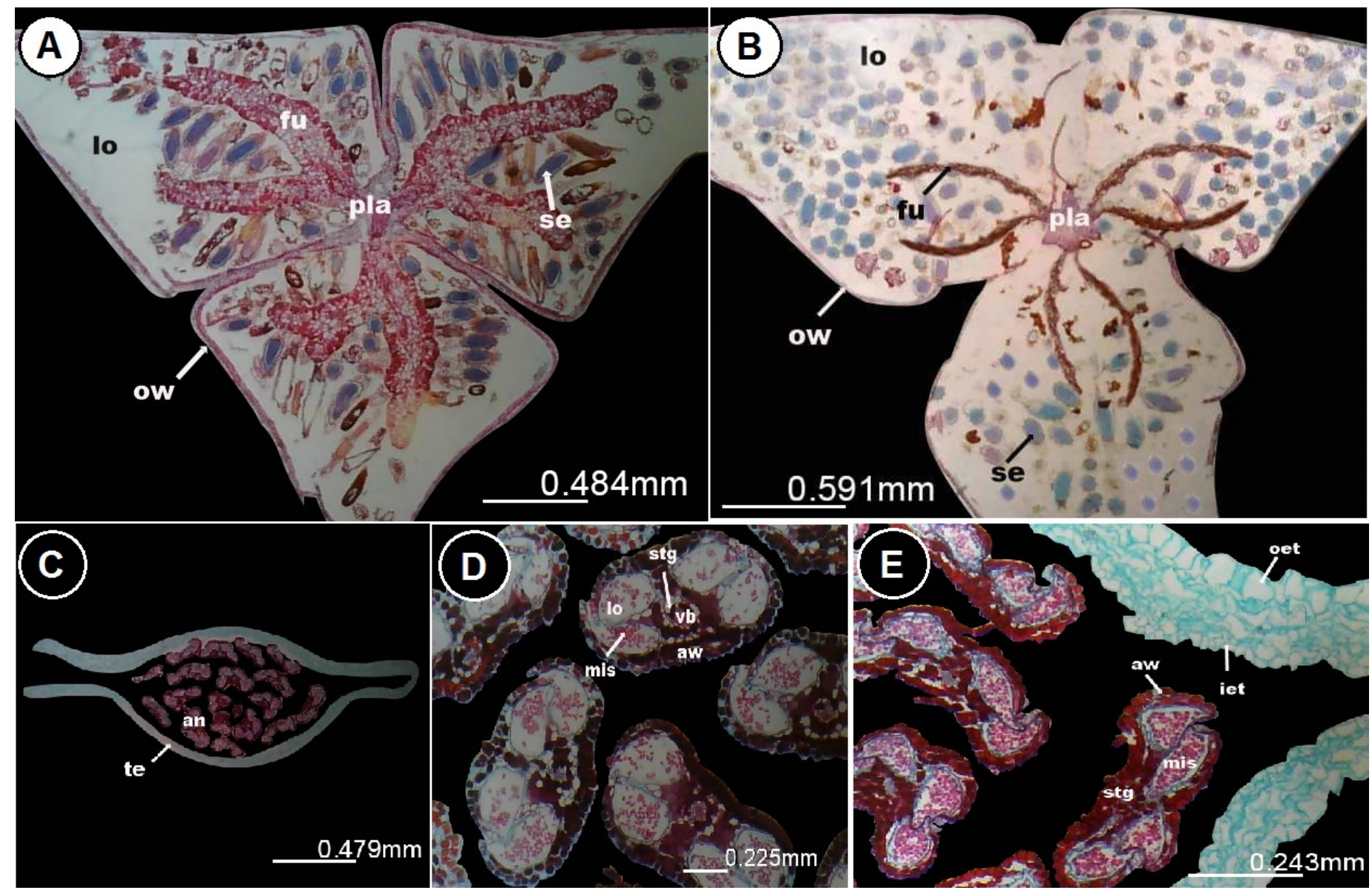

Figure 11. Transverse section of the carpellate flower of Begonia oxysperma (A) and Begonia ramosii (B) and staminate flower of Begonia ramosii (C-E). Abbreviations - an: anther; te: tepal; lo: locule; stg: stigma; vb: vascular bundle; mis: microsporangiospores; aw: anther wall; iet: inner epidermis of tepal; oet: outer epidermis of tepal; pla: placenta; fu: funiculus; ow: ovary wall; se: seed. 
temperature. Using transcriptome analysis, Dong et al. (2018) found that anthocyanin accumulation was employed as a common strategy by Begonia seedlings in resisting low temperature and high light stress. However, we found no significant correlation between light intensity and degree of anthocyanin pigmentation $(p>0.05)$.

The seeds of both species are very small, light and numerous which serve as an adaptation for wind dispersal (anemochory). When matured enough to produce seeds, capsules of both species turn brown and split between the locule and wing (Rubite, 2013). The seed and fruit characteristics of both species confer a wide range of dispersal. In our study, we found a positive correlation between average fruit length $(\mathrm{r}=$ $0.266 ; p=0.002)$ and total number of fruits $(\mathrm{r}=0.266 ; p=$ 0.002) with light intensity. Several studies (Jeong et al., 2009; Kessler \& Armitage, 1992) reported that begonias tend to have smaller and fewer flowers and fruits in the absence of adequate light. This only suggests that optimal light intensity to induce flowering and fruiting differs among Begonia species. Populations of Begonia spp. that are close to each other showed similar average fruit length and fruiting period which suggests localization of phenotypes. Functional traits are predictors of plants in response to environmental stimuli. Mt. Banahaw creates a micro-climate that allows the Begonia to develop functional characters. The presence of non-glandular trichomes provides a microlayer around the plant tissue in response to high relative humidity (Georgiev \& Naydenova, 2013). Thus, Begonia populations occurring on humid environments tend to possess lower trichome density while those with habitat of lower relative humidity tend to have higher trichome density.

The number of layers of collenchymatous cells on the cortex of stems for both species functions mainly for water storage and support. The presence of large amount of pectin on cell wall of collenchymatous cells makes them hydrophilic, allowing them to store water while the presence of cellulose and hemicellulose provide structural support (Jarvis \& Apperly, 1990). Meanwhile, the layer of parenchymatous cells in the cortex of $B$. oxyperma was relatively thicker than that of $B$. ramosii. This might be due to adaptation of the epiphytic $B$. oxyperma to conserve water intracellularly within the cortex. These parenchymatous cells are able to store water due to its thin wall and large air spaces, which are capable of elastic water storage (Borchert, 1994). The central pith region of both species also consisted mainly of parenchymatous cells which also function primarily for storage of water, mineral and other nutrients. Several populations of $B$. oxysperma including populations $6,8,10,11$ and 12 were observed to possess redstained cells near the vascular bundles at the pith region suggesting that it is a localized phenotype. This might be due to the presence of phenolic vacuolar inclusions (Gutmann, 1995). These phenolic compounds might contribute to resistance of $B$. oxysperma against herbivory and against the action of other parasitic microorganisms. Furthermore, these phenolic compounds might be a candidate component for possible antioxidant and antimicrobial property as in other related Begonia species (Isaivani et al., 2014; Jeeva \& Johnson, 2012; Kalpanadevi \& Mohan, 2012). The host plant of B. oxysperma might contribute to the formation of medullary vascular bundles. Dead woody trees provide drier environment to epiphytic $B$. oxysperma. As an adaptive mechanism, medullary cells develop on the large pith, allowing the cells along the pith to store water and starch (Mauseth, 1993). In our study involving 76 individual samples of $B$. oxysperma, 36 had Cyathea as their host, 9 had dead tree, 2 had Pandanus and the remaining 29 had a live woody tree as their host plant. Our results suggested that host tree with larger diameter provide greater substrate area and considerably greater amount of organic materials that epiphytic B. oxysperma can utilize. The presence of vascular cambium contributed to the secondary growth and rigidity of the stem of both species which serve primarily for support. Red-stained cells similar to those found on the leaves and stem of $B$. oxysperma were also observed on the transverse section of the petiole of $B$. ramosii due to the presence of phenolic compound which offers protection against herbivory.

The degree of histochemical stain absorption in the roots suggests that the main compound present in the cell walls of $B$. oxysperma is lignin, while in $B$. ramosii it is cellulose. The large amount of lignin present in between the cell walls of $B$. oxysperma cells serves as an adaptation among most epiphytes for water and ion regulation in apoplastic route (Dickison, 2000). The cells of the periderm of both species are both darkly stained due to the presence of suberin, which acts as chemical barrier to limit the extracellular and apoplastic transport of water and solutes in plant roots (Baxter et al., 2009). However, $B$. oxysperma was found to possess a thicker periderm compared to B. ramosii. This might serve as an adaptation to increase mechanical protection and prevent water loss, as occurs in most epiphytes (Moreira et al., 2008; Nawaz et al., 2013). Associated with the periderm of $B$. oxysperma are large, elongated parenchymatous cells, which comprise the cortex and potentially serve as a water reservoir.

The secondary phloem of root sections for both species was conspicuous due to red-stained cells which might be due to the presence of organic compounds specifically carbohydrates in the internal portion of the cells. Meanwhile, the xylem vessels of both species possessed thickened cell walls which provide maximum structural support by preventing them from collapsing in case of extreme root pressure. The diameter of xylem vessels 
of $B$. ramosii was found to be smaller compared to that of $B$. oxysperma, but occurred in higher frequency. Holste et al. (2006) observed that conduit diameters of xylem tend to be reduced and its number increases when subjected to environments with decreased water supply. Changes in the conduit diameter dramatically affect the hydraulic conductivity of roots. Thus, xylem vessels with smaller diameter would have lower hydraulic conductivity than those with larger diameter. To compensate for this, B. ramosii xylem vessels occurred in greater number. $B$. oxysperma, on the other hand, had xylem vessels with larger diameter but fewer in number.

Transverse sections of the leaves of $B$. oxysperma were generally thicker than $B$. ramosii which serve as an adaptation to exposure to full sunlight being an epiphyte. According to Kubinova (1991), leaves exposed to high light intensity generally develop multiple cell layers. Evans (1999) pointed out that the increase in total lamina thickness is mainly due to the greater palisade parenchyma, spongy parenchyma, and epidermal tissue thickness. B. oxysperma possessed noncontiguous stomatal clusters having groups of stomata that are separated by subsidiary cells. Each stomatal cluster consisted of 2 to 6 stomata. According to Hoover (1986), stomatal clustering serves as an adaptation for more efficient conservation of water. The density as well as distribution of trichomes along the leaf surface was observed to differ among $B$. oxysperma populations. Our results showed a positive correlation of stomatal density with altitude $(\mathrm{r}=0.479 ; p<0.01)$ and light intensity $(\mathrm{r}=0.412 ; p=0.003)$. We observed low stomatal density in areas with low light intensity suggesting that it is a localized phenotype. Together with other epidermal cells, trichomes determine the rate of epidermal transpiration and energy allocation on the leaves. According to Hall et al. (1993), non-glandular trichomes on leaf lamina reflect UV-B for photoprotection which could be the reason why most populations generally possess scarce trichome density on leaf abaxial surface and moderately dense trichomes on the adaxial side.

\section{Conclusions and Recommendation}

We have reported in this paper the functional traits of $B$. oxysperma and B. ramosii along the altitudinal gradients of Mt. Banahaw de Lucban using morpho-anatomical data. Even though the technique is relatively simple, we have provided evidences of how the environment shaped the morphology and anatomy of plants specifically Begonia. The two species are relatively similar in terms of their morpho-anatomy but some functional traits unique for each species were observed which confer adaptation. Our preliminary results are very important to understand the ecological adaptations of Begonia especially nowadays that we are experiencing climatic changes. Further explorations of wild Begonia populations found in other peaks of the Mt. Banahaw-San Cristobal Protected Landscape can be done to deliver a more extensive comparison of the Begonia species in the area. A study at the molecular level may also provide a more thorough analysis of the phenotypic variations among these Begonia species.

\section{Acknowledgements}

The authors would like to thank the Department of Environment and Natural Resources Provincial Office in Pagbilao, Quezon for providing the necessary permits for plant collection (Permit Nos. 2016-037; 2016-043). The forest rangers who helped the researchers during collection and the faculty members of the Department of Mathematics and Natural Sciences of Southern Luzon State University are also greatly acknowledged.

\section{Disclosure Statement}

The authors declared no conflict of interest or any financial interest or benefit that has arisen from the direct applications of this research.

\section{Literature Cited}

Abbott, R.J., 2017. Plant speciation across environmental gradients and the occurrence and nature of hybrid zones. Journal of Systematics and Evolution, 55(4):238-258.

Almazol, A.E. \& S.B. Quintana, 2009. Tree species composition and physiognomy of Kinabuhayan River riparian zones, Mt. Banahaw-San Cristobal Protected Landscape. Sylvatrop, 19 (1\&2): 29-56.

Banaticla, M.C.N., \& I.E. Buot Jr., 2005. Altitudinal zonation of pteridophytes on Mt. Banahaw de Lucban, Luzon Island, Philippines. Plant Ecology, 180:135-151.

Baxter, I., P.S. Hosmani, A. Rus, B. Lahner, J.O. Borevitz, B. Muthukumar, M.V. Mickelbart, L. Schreiber, R.B. Franke \& D.E. Salt, 2009. Root suberin forms an extracellular barrier that affects water relations and mineral nutrition in Arabidopsis. PLoS Genetics, 5(5):e1000492.

Borchert, R., 1994. Soil and stem water storage determine phenology and distribution of tropical dry forest trees. Ecology, 75(5):1437-1449.

Bosabalidis, A.M., G. Kofidis, \& M. Moustakas, 2003. Contemporary seasonal and altitudinal variations of leaf structural features in oregano (Origanum vulgare L.). Annals of Botany, 92 (5):635-645.

Bradshaw, A.D., 1965. Evolutionary significance of phenotypic 
plasticity in plants. Advances in Genetics, 13:115-155.

Cutuli, B., C. Lemanski, A. Fourquet, B.D. Lafontan, S. Giard, S. Lancrenon, A. Meunier, R. Pioud-Martigny, F. Campana \& H. Marsiglia, 1999. Environmental significance of anthocyanins in plant stress responses. Photochemistry and Photobiology, 70:1-9.

de Bello, F., A. Escudero, D.S. Pescador, \& F. Valladares, (2015). Plant trait variation along an altitudinal gradient in mediterranean high mountain grasslands: Controlling the species turnover effect. PLoS ONE, 10 (3):e0118876.doi:10.1371.

de Guia, A.P.O., N.D.C. Realubit, \& J.C.A. Jaluague, 2018. Distribution and diet of small nonvolant mammals along elevational gradients of Mt. Banahaw. Philippine Science Letters, 11(01):22-29.

Dickison, W.C., 2000. Integrative plant anatomy. Harcourt Academic Press, USA.

Dong, Y., Y. Qu, R. Qi, X. Bai, G. Tian, Y. Wang, J. Wang \& K. Zhang, 2018. Transcriptome analysis of the biosynthesis of anthocyanins in Begonia semperflorens under lowtemperature and high-light conditions. Forests, 9(87):1-17.

Evans, J.R., 1999. Leaf anatomy enables more equal access to light and $\mathrm{CO}_{2}$ between chloroplasts. New Phytologist, 143 (1):93-104.

Fitzpatrick, B.M., 2012. Underappreciated consequences of phenotypic plasticity for ecological speciation. International Journal of Ecology, doi:10.1155/2012/256017.

Gascon, C.N., R.C. Garcia, F.N. Beltran, W.C. Faller, \& M.A.R. Agudilla, 2013. Biodiversity assessment of Mt. Banahaw de Dolores, Philippines. Asian Journal of Biodiversity, 4:23-45.

Georgiev, G.I., \& G.K. Naydenova, 2013. Physiological function of non-glandular trichomes in red clover (Trifolium pretense L.). Journal of Agricultural Sciences, 58:217-222.

Griffith, T., \& S.E. Sultan, 2012. Field-based insights to the specialization: plasticity and fitness across habitats in a specialist/generalists species pair. Ecology and Evolution, 2 (4):778-791.

Guo, J., W. Han, \& M.H. Wang, 2008. Ultraviolet and environmental stresses involved in the induction and regulation of anthocyanin biosynthesis: A review. African Journal of Biotechnology, 7(25):4966-4972.

Gutmann, M., 1995. Improved staining procedures for photographic documentation of phenolic deposits in semithin sections of plant tissue. Journal of Microscopy, 179:277-281.

Hall, V.A., J.R. Pilcher, \& F.G. McCormac, 1993. Tephra dated lowland landscape history of the north of Ireland, A.D. 7501150. New Phytologist, 125:193-202.

Holste, E.K., M.J. Jerke, \& S.L. Matzner, 2006. Long-term acclimatization of hydraulic properties, xylem conduit size, wall strength and cavitation resistance in Phaseolus vulgaris in response to different environmental effects. Plant Cell and Environment, 29(5):836-843.

Hoover, W.S., 1986. Stomata and stomatal clusters in Begonia: Ecological response in two Mexican species. Biotropica, 18:16-21.

Hughes, M, 2008. An annotated checklist of Southeast Asian Begonia. Edinburgh: Royal Botanic Garden Edinburgh.

Hughes, M, C.I. Peng, C.W. Lin, R.R. Rubite, P. Blanc, \& K.F. Chung, (2018). Chloroplast and nuclear DNA exchanges among Begonia sect. Baryandra species (Begoniaceae) from Palawan Island, Philippines, and descriptions of five new species. PLoS ONE 13(5): e0194877. https:// doi.org/10.1371/journal.pone.0194877.

Isaivani, I., R. Gomathi, \& S. Karpagam, 2014. Antimicrobial and in vitro antioxidant potential of Begonia dipetala Graham. International Journal of Pharmaceutical Sciences Review \& Researh, 27(2):382-386.

Jarvis, M.C., \& D.C. Apperly, 1990. Direct observation of cell wall structure in living plant tissues by solid-state ${ }^{13} \mathrm{C}$ NMR spectroscopy. Plant Physiology, 92:61-65.

Jeeva, S., \& Johnson, M, 2012. Anti-bacterial and phytochemical studies on methanolic extracts of Begonia floccifera Bedd. flower. Asian Pacific Journal of Tropical Medicine, 2:S151-S154.

Jeong, K.Y., M. McMahon, C.C. Pasian, \& D. Tay, 2009. Growth of six Begonia species under shading. The Open Horticulture Journal, 2:22-28.

Kalpanadevi, V., \& V.R. Mohan, 2012. In vitro antioxidant studies of Begonia malabarica Lam. and Begonia floccifera Bedd. Asian Pacific Journal of Tropical Medicine, 2:S1572S1577.

Kessler, J.R., \& A.M. Armitage, 1992. Effects of shading on growth rate, flower initiation and flower development of Begonia $\times$ Semperflorens-cultorum. Journal of Horticultural Science, 67(6):849-854.

Körner, C., 2007. The use of altitude in ecological research. Trends in Ecology \& Evolution, 22:569-574.

Kubinova, L., 1991. Stomata and mesophyll characteristics of barley leaf as affected by light: Stereological analysis. Journal of Experimental Botany, 42(241):995-1001.

Mauseth, J.D., 1993. Medullary bundles and the evolution of cacti. American Journal of Botany, 80:928-932.

Moreira, A.S., P. Franco, \& R.M. Isaias, 2008. Comparative 
anatomy of the absorption roots of terrestrial and epiphytic orchids. Brazilian Archives of Biology and Technology, 51 (1):83-93.

Nawaz, T., M. Hameed, M. Ashraf, S. Batool, \& N. Naz, 2013. Modifications in root and stem anatomy for water conservation in some diverse blue panic (Panicum antidotale Retz.) ecotypes under drought stress. Arid Land Research and Management, 27(3):286-297.

Robil, J.L.M., \& V.S. Tolentino, 2016. Histological localization of tannins at different developmental stages of vegetative and reproductive organs in Medinilla magnifica (Melastomataceae). Flora, 217:82-89.

Rubite, R.R., 2013. Begonia section Petermannia of Luzon Island, the Philippines. Philippine Journal of Science, 142:183-197.

Rubite R.R., M. Hughes, G.J. Alejandro \& C.I. Peng, 2013. Recircumscription of Begonia sect. Baryandra (Begoniaceae): Evidence from molecular data. Botanical Studies, 54(38): 1-5.

Ruzni, S.E. (1999). Plant Microtechnique and Microscopy. Oxford University Press. Retrieved from: http:// microscopy.berkeley.edu/Resources/book.html.

Santiago, J.O., \& Buot, I.E., 2015. Conservation status of selected plants of Mount Banahaw-San Cristobal Protected Landscape, Quezon Province, Philippines. International Peer Reviewed Journal, 16: doi: http://dx.doi.org/10.7718/ ijec.v16i1.1017.

Schlichting, C, \& D.H. Smith, 2002. Phenotypic plasticity: Linking molecular mechanisms with evolutionary outcomes. Evolutionary Ecology, 16:189-211.

Shah, S., K.K. Shrestha, \& C. Scheidegger, 2019. Variation in plant functional traits along altitudinal gradient and land use types in Sagarmatha National Park and buffer zone, Nepal, American Journal of Plant Sciences. 10:595-614

Tolentino, V.S., 1995. Handbook on Botanical Microtechnique. Part 1. Ateneo de Manila University Press, Quezon City, Philippines.

Yuliani, S., B. Yanuwiadi, \& A.S. Leksono, (2015). The relationship between habitat altitude, environmental factors and morphological characteristics of Pluchea indica, Ageratum conyzoides and Elephantopus scaber. OnLine Journal of Biological Sciences, 15(3):143-151. 